\title{
PUBLICAR OU ARQUIVAR? A REVISTA DO IHGB: UM PERIÓDICO A SERVIÇO DO IMPÉRIO NO OITOCENTOS BRASILEIRO*
}

\author{
PUBLISH OR FILE? THE JOURNAL OF THE IHGB: A NEWSPAPER IN \\ THE SERVICE OF THE EMPIRE IN THE BRAZILIAN NINETH CENTURY
}

Luís César Castrillon Mendes**

\begin{abstract}
Resumo: Durante o período regencial, em 1838, nascia o Instituto Histórico e Geográfico Brasileiro (IHGB), uma agremiação que priorizava, dentre outras atribuições, a construção de uma escrita histórica para o jovem Estado brasileiro. Logo em seguida, como uma das formas de cumprir estes propósitos, criava-se a sua Revista Trimestral (RIHGB). Neste texto se discute a operação historiográfica empreendida pelo IHGB, a partir da análise dos conteúdos veiculados nas páginas do periódico desta Instituição. Elegeu-se, para tanto, as RIHGB que foram publicadas entre 1839 e 1889, vale dizer do início de sua circulação até o final da Monarquia constitucional brasileira.
\end{abstract}

Palavras-chave: IHGB. Periódico. Escrita da História. Segundo Reinado.

\begin{abstract}
During the Regency period in 1838, was born the Brazilian Historical and Geographical Institute (IHGB), an association which emphasized, among other things, the construction of a historical writing for the young Brazilian state. Soon after, as a way to fulfill these purposes creates its Quarterly Magazine (RIHGB). This paper discusses the historiographical operation undertaken by IHGB, from the analysis of the content carried in the pages of the journal of this institution. Was elected to both the RIHGB that circulated between 1839 and 1889, that is the beginning of their movement by the end of the Brazilian constitutional monarchy.
\end{abstract}

Keywords: IHGB. Journal. Writing of History. Second Reign.

Tendo sido criado em 1838, em um dos momentos particularmente conturbados da história do Brasil, o Instituto Histórico e Geográfico Brasileiro (IHGB) desempenhou importante papel no processo de consolidação do Estado imperial, ao lado de outras instituições tais como a Academia Imperial de Belas Artes (1826), o Imperial Colégio de Pedro II (1837) e o Arquivo Público do Império (1838). Nas páginas de seu periódico foram publicados vários documentos cuidadosamente selecionados para a constituição de uma

\footnotetext{
* Este texto é uma adaptação de um dos capítulos de minha Dissertação de mestrado intitulada: Publicar ou arquivar? A Revista do IHGB e a escrita da História Geral do Brasil (1839-1889), defendida em 2011.

** Professor Adjunto da Universidade Federal da Grande Dourados - UFGD. E-mail: 1.cesar69@ hotmail.com
} 
memória oficial do Estado fundado em 1822, que por sua vez, serviria de subsídios para a escrita futura da história.

Na Revista do IHGB, em circulação ininterrupta desde 1839, havia seleção de documentos do passado remoto privilegiando dados sobre determinadas regiões do território em detrimento de outras. Mas, o periódico não daria visibilidade somente para as memórias garimpadas junto ao passado colonial; alguns artigos sobre acontecimentos contemporâneos viriam à público, assim como juízos e pareceres de obras, deliberações e determinações das diversas comissões de trabalhos, relatórios e discursos, transcritos nas Atas das sessões ordinárias e sessões aniversárias, dando a perceber o complexo trabalho realizado pela instituição.

Dessa forma, pode-se pensar que o Instituto, que mais tarde seria conhecido como a "Casa da Memória Nacional", , trazia como principal objetivo a construção de uma História Geral do Brasil, a ser escrita preferencialmente por um brasileiro de nascimento, a partir dos novos padrões exigidos pela história disciplinar e científica, própria do Oitocentos.

Diante do exposto, este texto objetiva apresentar a Revista do IHGB enquanto um ambicioso e bem-sucedido projeto de construção nacional, no qual se preocupava basicamente na seleção, coleta, sistematização e publicação de documentos para a escrita de uma História Geral do e para o então jovem Estado monárquico brasileiro.

O IHGB tinha como uma das metas principais criar agremiações congêneres nas demais províncias a fim de melhor coletar e sistematizar dados para serem analisados a partir do centro, ou seja, a partir da Corte fluminense. Nesse contexto, por exemplo, foram fundados o Instituto Arqueológico e Geográfico de Pernambuco (IAGP), já em 1862, além do Instituto Histórico e Geográfico de São Paulo (IHGSP), em 1894 e o Instituto Histórico de Mato Grosso (IHMT), no contexto das comemorações do bicentenário de Cuiabá, em $1919^{2}$.

Neste contexto, os trabalhos que conseguiram espaço no periódico do Instituto serão analisados enquanto resultantes das lutas de representação no interior do grêmio. Um procedimento que Michel de Certeau (2002, p. 66) denominou “Operação historiográfica”, com seus ditos e não ditos; constituindo dessa maneira, um lugar socioeconômico, político e

\footnotetext{
1 A partir de 1992, o Instituto passa a ser referenciado nos Estatutos como a Casa da Memória Nacional. (WEHLING, 2010, p. 132).

2 Atualmente existem importantes trabalhos acerca desses congêneres regionais. Conferir Mahl (2001 e 2008), Leotti (2013) e Ribeiro (2011), dentre outros.
} 
cultural de produção discursiva, qual seja, o centro do Império, uma sociedade de Corte articulada aos propósitos do Estado monárquico referentes à construção nacional.

\section{A Revista do IHGB enquanto fonte e/ou objeto para pesquisa}

Eleger periódicos como fontes e/ou objeto para a pesquisa requer alguns cuidados metodológicos. Assim como qualquer fonte a ser trabalhada, não se pode confiar na retórica da documentação e nem em seus discursos unificadores e homogeneizadores. Neste sentido, Tânia de Luca (2008, p. 140), adverte que deve-se atentar para a disponibilidade das longas séries; o que, no caso da Revista do IHGB, uma publicação ininterrupta desde 1839 até os dias de hoje, é um dado significativo pela longevidade e pela facilidade de acesso, já que se encontra disponível em versão digital.

Para o uso das revistas, continua a autora, é preciso observar as motivações que levaram à decisão de dar publicidade a alguma coisa. Essas observações vão ao encontro da afirmação de Jean François Sirinelli, em que uma revista é um lugar de fermentação intelectual e de relação afetiva, ao mesmo tempo viveiro e espaço de sociabilidade. Nela reside a importância de se identificar autores, editores, colaboradores mais assíduos e os textos selecionados para a veiculação, assim como observar as ligações com diferentes poderes e interesses financeiros, bem como ao público a que se destina (SIRINELLI, 1996, p. 249).

O IHGB, por meio de sua Revista, trataria de idealizar as diretrizes para um projeto de integração das diversas províncias à Corte, a partir de um monopólio do saber historiográfico. Com base nas questões do tempo presente se escolheria no passado fatos e personagens para fazerem parte dessa história nacional.

Uma rígida seleção do material era efetuada pelas diversas comissões de trabalhos. Assuntos da história contemporânea, geralmente tinham como destino o arquivo. Temas do passado colonial, principalmente sobre os indígenas, as viagens de exploração ao interior e as histórias das províncias eram levadas a público de imediato.

O brasilianista norte-americano Rollie E. Poppino, um dos primeiros a realizar um levantamento envolvendo o conteúdo do periódico, em 1953, observou que trabalhos sobre a História totalizavam $45 \%$ do material publicado no primeiro século de existência da Revista do Instituto, enquanto que trabalhos de Geografia e Geologia 18\%, as biografias, $16 \%$ e as áreas de Antropologia e Etnologia, apenas 5\%. Em seguida o autor dividiu o conteúdo de 
História em cinco partes: política, social, religiosa, militar e econômica. Além disso, Poppino delimitou cronologicamente em quatro períodos de aproximadamente 25 anos: 1839-1864; 1865-1889; 1890-1914 e 1915-1938 (R.IHGB, 1977, p. 285-305).

Aproveitando os dados proporcionados pelo autor, quanto ao intervalo temporal entre 1839-1889, pôde-se inferir que, durante esse período, a circulação da Revista no Segundo Reinado, a seção de história política ocupou um total de $90 \%$ das publicações sobre essa área do conhecimento, enquanto que a Social, 42\%; a Religiosa, 38\%; a Militar, 16\% e a Econômica, $14 \%$.

Das produções de âmbito historiográfico dos associados, destacaram-se os temas do Descobrimento e da Independência. Tais escolhas estavam associadas à busca de marcos da gênese da nação. Em um passado distante temporalmente estavam os elementos fundadores da nacionalidade, e, a Independência, nos termos de Valdei Lopes Araújo (2008, p. 155), tornava-se o marco de uma abertura epistemológica, um evento a partir do qual todo o passado colonial podia ser compreendido como a formação da nacionalidade. Dessa forma, para o referido historiador, a Independência foi definida como princípio organizador da narrativa histórica, marcado pela continuidade da Casa de Bragança, porém sem a possibilidade de se confundirem as duas nações, portuguesa e brasileira. Nas páginas da Revista do IHGB firmava-se a compreensão de que os sentimentos de identidade nacional e o próprio processo de independência política estiveram sempre presentes ao longo da história colonial (ARAUJO, 2008, p. 160).

Ao elaborar um estudo precursor sobre o IHGB, Manoel Salgado Guimarães analisou esta instituição articulada com a ideia de construção da nação e civilização no Brasil Imperial. Em relação à Revista, afirmou que ela se constituía em um espaço privilegiado para se rastrear o projeto ambicioso do Instituto Histórico, pois além de registrar as suas atividades por meio de relatórios, divulgar cerimônias e atos comemorativos diversos, suas páginas se abriram à publicação de fontes primárias como forma de preservar a informação nelas contidas de artigos, biografias e resenhas de obras (GUIMARÃES, 1988, p. 20).

O mesmo autor observou também a incidência de três temas predominantes no interior da Revista do IHGB, a saber: 1) a questão da "problemática" indígena; 2) as viagens e explorações ao interior do território e 3) o debate sobre a história regional. Em muitos artigos esses temas se entrecruzavam, particularmente os dois primeiros. Essas três temáticas, 
responsáveis por $73 \%$ das publicações, indicam, pois, quais assuntos estavam em evidência à época.

Lúcia Paschoal Guimarães, por sua vez, abordou o conteúdo veiculado na Revista segundo a divisão em documentos "contemporâneos" e "não contemporâneos". Tendo como objetivo avaliar a produção intelectual dos consócios do Instituto, durante o Segundo Reinado, a autora fez uma distinção entre "Memória" (documentos coligidos do passado distante) e "História" (produção contemporânea dos sócios). Sua conclusão foi a de que a quantidade dos documentos "não contemporâneos" publicados foi maior do que o triplo dos escritos contemporâneos, o que a levou a afirmar que os intelectuais do IHGB se esmeraram no que diz respeito à Memória e que quanto à História, eles deixaram a desejar (GUIMARÃES, 1995, p. 513). Para essa quantificação a autora não considerou os necrológios dos sócios, que eram redigidos pelos oradores nas Sessões Aniversárias, justificando que cabia ao próprio associado em vida fornecer as informações que julgasse relevantes. Tampouco levou em consideração, no seu inventário, os relatórios dos primeiros secretários, os discursos dos presidentes e as biografias das "distintas personalidades".

É bem verdade que o Instituto se dedicou a construir um banco de memórias cuja visibilidade se deu a partir da publicação na sua Revista. Esses vestígios do passado eram selecionados em arquivos no Brasil e no exterior e submetidos aos métodos da crítica documental. Para Temístocles Cezar, o fato de se produzir uma memória nacional, por parte dos membros do IHGB, não implica o abandono da História, pois tratam-se de escolhas políticas e epistemológicas (CEZAR, 2004, p. 55). Além disso, Michel de Certeau (2002, p. 81) já advertia que "em história, tudo começa com o gesto de separar, de reunir, de transformar em documentos certos objetos distribuídos de outra maneira”. Não por acaso, um dos principais objetivos do grêmio fluminense, de acordo com o primeiro artigo de seus estatutos era:

O Instituto Historico e Geographico Brazileiro tem por fim colligir, methodisar, publicar ou archivar os documentos necessarios para a historia e geographia do Imperio do Brazil; e assim tambem promover os conhecimentos destes dous ramos philologicos por meio do ensino publico, logo que o seu cofre proporcione esta despeza (R.IHGB, 1839, p. 18).

A grande maioria dos temas veiculados na Revista contemplava o período colonial, porém, havia espaços do periódico nos quais apareciam as manifestações "contemporâneas" dos sócios. É justamente nas seções destinadas a biografias, nos elogios históricos e nos 
discursos e relatórios que se fixavam pressupostos teórico-metodológicos e manifestações políticas. Esses procedimentos de se privilegiar indivíduos e episódios, ou seja, escolher vultos nacionais para protagonizarem a história pátria e formas de se produzir a escrita da história, denotam que discursos e relatórios, bem como os elogios aos mortos manifestavamse disseminados em diferentes partes do periódico e eram submetidos também às regras da operação historiográfica.

Havia uma lógica de publicação quanto a temporalidade do fato: normalmente assuntos recentes não eram publicados. Porém houve algumas, em verdade poucas, exceções à regra determinada pelo Instituto de não dar visibilidade a acontecimentos contemporâneos, cujos personagens envolvidos ainda encontravam-se vivos. Havia, nos termos dos consócios, um "Tribunal da Posteridade" que condenava documentos contemporâneos e comprometedores ao arquivo. Assim, na análise dos artigos destinados à Revista tornam-se interessantes as articulações entre a data das suas publicações e os seus respectivos contextos históricos vividos pela Monarquia.

Deste modo, pode-se afirmar que predominava entre os intelectuais do IHGB, aliado ao projeto de nação por parte da Monarquia, o desejo de se construir uma "História"; absoluta, científica e moderna. Em si e para si; que rompesse com a historiografia antiga e medieval e as "histórias" dos tempos anteriores, designando assim um singular coletivo, nos termos de Reinhart Koselleck (2006, p. 119). Dessa forma, fundamentava-se a identidade da nação, visando, no plano interno, manter a unidade territorial e, no externo, legitimar a condição singular de governo monárquico em meio às Repúblicas hispano-americanas.

\section{$O$ Tribunal da Posteridade: "a História deve ser imparcial e isenta das paixões do tempo presente"}

Os primeiros secretários eram os responsáveis pelo efetivo andamento da agremiação, normalmente acumulando cargos e funções. O cônego Januário da Cunha Barbosa (1780-1846), por exemplo, foi diretor da comissão que elaborou os primeiros estatutos, chefe da comissão de redação da Revista, da biblioteca e do arquivo. Francisco Adolfo de Varnhagen (1816-1878), no curto período de permanência na primeira secretaria, organizou a biblioteca. O cônego Joaquim Caetano Fernandes Pinheiro (1825-1876), ficou à frente da secretaria por 16 anos, fazendo alterações no formato da Revista. Eram a eles que pertenciam as prerrogativas da escolha do 
que se deveria publicar e o que seria destinado aos arquivos. Para as Sessões Magnas de aniversário, eles elaboravam seus relatórios minuciosos dos trabalhos realizados durante o ano corrente, nos quais selecionavam/exaltavam personagens e acontecimentos que mais lhes conviessem.

\section{Temas Regionais}

A ocorrência de temas regionais, localizados nas províncias do Império, segue uma lógica de se arquivar os assuntos da contemporaneidade e de se publicar documentos sobre o passado colonial que trouxessem informações para a legitimação e consolidação da unidade territorial brasileira, além de fatos e personagens "dignos" de lembrança e exemplos a serem seguidos.

$\mathrm{Na}$ análise do conteúdo, veiculados na Revista, nota-se que há uma predominante presença do Rio de Janeiro nas páginas da Revista do IHGB, 74 menções! O que surpreende é que no período estudado a segunda província cuja presença era constante foi Mato Grosso, o que evidencia a preocupação para com a história regional. O fato de Mato Grosso aparecer tão seguidamente na Revista, assim como Rio Grande do Sul, Pará e Amazonas, regiões de fronteira nacional, deixa em evidência a preocupação do Estado imperial com os assuntos relacionados à delimitação das raias fronteiriças. E isto fica mais patente quando se verifica, no caso de Mato Grosso, sua presença nos volumes publicados no período que antecedeu a Guerra da Tríplice Aliança com o Paraguai (1864-70)³.

Entretanto, após o término do conflito até o final do período imperial, em 1889, Mato Grosso perde a ênfase na Revista, cedendo lugar para outras regiões como Pernambuco e Rio Grande do Sul. Acontece que essas regiões não se fizeram tão presentes na Revista, nos primeiros anos de sua publicação, já que num passado recente foram cenários de conflitos contra a ordem estabelecida pelo governo no Rio de Janeiro. Pernambuco pela Revolução de 1817 e a Confederação do Equador, em 1824, ao passo que o Rio Grande do Sul pelo Movimento Farroupilha (1835-1845). Muitas das personagens que participaram nesses levantes ainda estavam vivas e algumas delas faziam parte do Instituto, como por exemplo, o sócio fundador Raimundo José da Cunha Matos (1776-1839). No seu elogio histórico, no primeiro volume da Revista, o orador evidenciou justamente a participação do marechal de campo na Revolução Pernambucana, de 1817.

\footnotetext{
${ }^{3}$ Conferir principalmente: R.IHGB, 1857; R.IHGB, 1862, e R.IHGB, 1865. O periódico do Instituto Histórico e Geográfico Brasileiro encontra-se digitalizado e disponível em: http://www.ihgb.org.br/rihgb.php
} 
A história das diversas províncias foi abordada nas páginas da Revista segundo uma perspectiva a partir da Corte, a fim de reafirmar uma ligação orgânica entre as regiões e o centro político do Império. Segundo Manoel Salgado Guimarães, tratava-se de selecionar nos temas da história regional elementos que corroborassem uma perspectiva centralizadora, respaldada pelo conhecimento da História entre as diversas partes integrantes da nação (GUIMARÃES, 1989, p. 36).

Nesse sentido, é interessante o parecer da Comissão de História sobre um documento, ofertado ao Instituto pelo general José Inácio de Abreu e Lima (1796-1869), acerca da participação do então governador de Pernambuco Caetano Pinto de Miranda Montenegro (1748-1827) no conflito de 1817:

Conquanto um tal documento seja na verdade de muito preço, não convém todavia publicá-lo pelo comprometimento que sua publicação poderia levar a pessoas ainda existentes; e por isso a Comissão é de parecer que o sobredito documento seja guardado nos arquivos do Instituto até que todos os nomes nesse documento mencionados tenham comparecido perante o Tribunal da Posteridade (R.IHGB, Ata da sessão de 19/12/1839).

Porém, esse mesmo Tribunal não condenou um trabalho do médico e poeta Domingos José Gonçalves de Magalhães (1811-1882) intitulado Memoria historica e documentada da revolução da provincia do Maranhão desde 1839 até 1840, premiado pelo IHGB em 1847 e publicado já em 1848. Magalhães na qualidade de secretário do então presidente dessa província, Luís Alves de Lima e Silva (1803-1880), encarregava-se de registrar os feitos do futuro duque de Caxias ao sufocar a Insurreição denominada "Balaiada", cujos chefes eram um vaqueiro cafuzo - Raimundo Gomes, um "fazedor de balaios" e um negro - Dom Cosme. A origem social dessas personagens sugere o motivo pelo qual esse assunto delicado passou pelas comissões do IHGB.

No entanto, quando a mesma dupla Magalhães e Lima e Silva estiveram no Rio Grande do Sul, com o intuito de sufocar o movimento farroupilha, um pela pena e outro pela espada, o relato do futuro visconde do Araguaia não foi publicado. Segundo Lúcia Guimarães (1995, p. 534), o conflito no Sul envolvia estancieiros e charqueadores, com complicações internacionais. Somente a partir de 1880 a Farroupilha vai aparecer na Revista, por iniciativa de Tristão de Alencar Araripe (1821-1908), fundamentado nas observações de Gonçalves de Magalhães da década de 1840 (Cf. R.IHGB, 1880, 1882 e 1884). 
A Bahia, primeira sede do governo lusitano na América portuguesa, esteve em destaque nos anos iniciais de circulação da Revista. As temáticas versavam sobre o passado colonial: tribos indígenas, projetos de estradas, relatórios sobre minas e principalmente informação sobre uma "antiquíssima cidade abandonada". Uma das primeiras fixações do Instituto foram pesquisas no intuito de se descobrir ruínas de civilizações nos moldes das encontradas na América espanhola, cujas notícias indicavam a existência de ruínas pré-cabrálicas no interior da Bahia. Tal assunto foi tratado na Relação Historica de uma occulta e grande povoação antiquissima, sem moradores, que se descobriu no anno de 1753, nos sertões do Brazil. (R.IHGB, 1839, 1841, 1844, 1845 e 1848).

\section{Sobre os acontecimentos contemporâneos}

Uma das regras mais rígidas do Instituto, a de não dar publicidade aos acontecimentos contemporâneos, sempre esteve ameaçada por iniciativas dos consócios para que não se perdessem determinados fatos relevantes para a Monarquia bem como promover as suas inserções no conjunto de matérias veiculadas na Revista.

A primeira ideia de se preservar acontecimentos recentes, valendo-se inclusive do uso de "fontes orais fidedignas" partiu do conselheiro Euzébio de Queirós Coutinho Mattoso Câmara (1812-1868), na qual se devia convidar Joaquim Gonçalves Ledo (1781-1847), José Clemente Pereira (1787-1854) e Januário da Cunha Barbosa a fim de "coligir e escrever tudo aquilo que possa esclarecer ao historiador sobre a gloriosa época da nossa independência" (R.IHGB, Ata da sessão de 20/04/1839). O cônego Cunha Barbosa, na sessão de 18/05/1839, propôs que se indicassem dois sócios a fim de elaborarem uma espécie de efemérides, notando por dia os fatos de maior interesse para a história do Brasil. Na sessão de 01/08/1840, Clemente Pereira sugeriu a criação de um livro intitulado Crônica do Senhor Pedro II e que se nomeasse uma comissão de cinco membros para coligir e coordenar os fatos mais notáveis ocorridos durante o ano para serem apresentados nas Sessões Aniversárias. Desses projetos o único que vingou foi o das efemérides, que passaram a ser lidas semestralmente, porém, como era de se esperar, não foram publicadas.

Outra manifestação da história contemporânea foi a edição de um volume suplementar da Revista, contendo composições dos sócios, dedicadas à morte prematura do príncipe D. Affonso em 1847, herdeiro da Coroa, aos dois anos de idade. O primeiro secretário, Manoel Ferreira Lagos (1816-1871), informou que os trabalhos seriam submetidas à votação antes de 
serem impressos. Uma das produções, a do médico Bento Mure (1809-1858), foi barrada no escrutínio secreto. A mesa diretora assim se manifestou após a votação: “o discurso do Sr. Mure, não só por conter muitas ideias extemporâneas e ofensivas na sua parte prosaica, mas ainda por se achar já impressa a parte poética, o que vai de encontro ao programa publicado pelo Instituto". Depois de uma "animada discussão", de acordo com o relator da Ata dessa sessão, veio o veredicto: "Que sejam impressos todos os trabalhos lidos na assembleia de $1^{\circ}$ de julho, menos o do Sr. Mure” (R.IHGB, Ata da sessão de 03/07/1847).

O parecer do IHGB motivou uma intensa troca de cartas entre o médico, que exigiu a restituição do manuscrito, e o primeiro secretário, que exigiu a devolução do diploma de sócio. Diante do impasse, o Instituto deliberou que se devolvesse o texto, desde que ficasse arquivada uma cópia do mesmo, porém, Bento Mure não devolveu o diploma, justificando o respeito que consagrava a quem o enviou e assinou, assim como ao Instituto que o teria adotado sem nenhuma solicitação de sua parte (R.IHGB, Ata da sessão de 22/07/1847). O médico estava se referindo a Januário da Cunha Barbosa, falecido no ano anterior, que antecedeu Manoel Ferreira Lagos na primeira secretaria.

Em 1863, o sócio Felizardo Pinheiro de Campos (1813-1889) viu a necessidade de compor uma obra cujo título era: Fastos do feliz e glorioso reinado do Sr. D. Pedro II. Apesar da indicação do próprio monarca de se escrever sobre os acontecimentos de seu reinado e das intensas referências, expressas nas Atas, acerca dos temas contemporâneos como as "rebeliões" regenciais e o processo de independência, a comissão de trabalhos históricos decidiu pelo arquivamento, achando a iniciativa "desaconselhada, desnecessária e inconveniente" (R.IHGB, Ata da sessão de 08/05/1863).

Pinheiro de Campos na sessão de 03/07/1863 reformulou sua proposta, agora sob o enunciado: Bosquejo do atual reinado desde a aclamação da maioridade de S. M. I. ou apontamentos para a história do Brasil. O primeiro secretário Fernandes Pinheiro assim se manifestou sobre a iniciativa: "razões imperiosas, que já submetti ao vosso discernimento, impoem-me silencio a respeito d'este trabalho do nosso colega" (R.IHGB, 1865, p. 335).

Durante o conflito no Prata entre a Tríplice Aliança e o Paraguai, o referido Tribunal da Posteridade esteve bem flexível às publicações de trabalhos contemporâneos, quase que simultaneamente aos acontecimentos. Em 1869, por exemplo, Alfredo d'Escragnolle Taunay (1843-1899), orador do Instituto, teve publicada a sua memória Viagem de regresso de MatoGrosso á côrte. No ano seguinte, saiu no periódico uma memória que havia sido lida na 
sessão de 03/10/1869, o combate da ilha do cabrita, do primeiro secretário Manoel Duarte Moreira de Azevedo (1832-1903), uma narrativa de um episódio da guerra na qual se evidenciava a coragem dos combatentes brasileiros, por meio de pequenas biografias (R.IHGB, 1869, p. 5-52 e R.IHGB, 1870, p. 5-20).

Apesar da não publicação da grande maioria, estes temas da história contemporânea eram lidos e discutidos nas sessões, evidenciando as preocupações com a história do tempo presente, as quais podem ser encontradas somente nos arquivos do Instituto, no Rio de Janeiro.

\section{O passado em Revista: temáticas "sugeridas" para a escrita histórica da nação}

Na Revista a produção intelectual dos consócios acerca da escrita da História, constituiu-se em uma minoria se comparada com os documentos do período colonial, ainda mais se não forem levadas em consideração as biografias dos "brasileiros distintos" e os elogios históricos dos sócios falecidos. Em vista destas constatações, foram incluídas, na análise das modalidades temáticas veiculadas no periódico, essas duas categorias de produção, já que além do número expressivo de ocorrência na Revista, sujeitavam-se igualmente aos procedimentos da operação historiográfica.

\section{Biografias dos brasileiros "distintos"}

O IHGB priorizou a produção de biografias de personalidades ilustres do passado a fim de servir de exemplo aos brasileiros do presente. A elaboração das biografias permaneceu como uma prática enfatizada principalmente nos anos iniciais de circulação da Revista. $\mathrm{O}$ expressivo número na primeira década de funcionamento do Instituto sugere a incorporação da categoria biografia ao projeto de elaboração da narrativa nacional. $\mathrm{O}$ mesmo frenesi em se coligir documentos da história pátria se verificou com a seleção de personagens a serem biografados. Entre 1850 e 1859 houve uma significativa queda nessas produções. Em 1851 aparece apenas uma biografia publicada e entre os anos de 1853 e 1858 elas praticamente desaparecem do periódico, salvo em 1855 e 1856, nos quais saíram à luz apenas quatro biografias.

Um dos motivos pelo súbito afastamento das biografias da Revista pode ser identificado ao verificar os temas publicados nesses anos. Houve uma ênfase em dar visibilidade a assuntos relacionados a regiões de fronteira como Rio Grande do Sul e Mato Grosso, que 
foram palcos da guerra com a República do Paraguai, bem como começaram a sair dos arquivos as primeiras memórias sobre os conflitos regenciais em Pernambuco e no Rio Grande do Sul.

Maria da Glória Oliveira chama atenção para alguns aspectos na análise da seção de biografias da Revista do IHGB: a primeira delas é o título em aberto "etc.", ao final do longo título, marcado por variações que, de imediato, sugerem impasses e hesitações dos seus colaboradores, principalmente quanto à demarcação da nacionalidade dos eleitos para a posteridade (OLIVEIRA, 2007, p. 154-178). O título da seção, oscilando entre "brasileiros ilustres" e "indivíduos ilustres", permitia a inserção de biografados que não fossem brasileiros de nascimento, assim como legitimava biógrafos que estavam tendo sua nacionalidade questionada, como é o caso de Varnhagen, o membro do IHGB que mais produziu biografias, num total de vinte e quatro.

Na escrita biográfica de 1843 sobre José Fernandes Vieira, português de nascimento, o futuro visconde de Porto Seguro já advertia que o Instituto deveria publicar também "biografias de varões illustres, que posto não sejam brasileiros por nascimento, todavia o são por acções gloriosas, e por haverem passado grande parte de sua vida n'este paiz" (R.IHGB, 1843, p. 82).

Além do visconde de Porto Seguro, outros sócios se destacaram na contribuição nessa parte da Revista, são eles: os primeiros secretários Januário da Cunha Barbosa, Joaquim Caetano Fernandes Pinheiro e Manuel Duarte Moreira de Azevedo, com 11, 9 e 8 biografias respectivamente, além dos historiadores Joaquim Norberto de Sousa e Silva (1820-1891), com 7, e João Manuel Pereira da Silva (1817-1898), com 5. Desse expressivo número do gênero, apenas cinco mulheres figuraram nessa galeria, quatro trazem a autoria de Sousa e Silva, futuro presidente do IHGB. A outra biografia, a da poetisa fluminense Narciza Amália de Campos (1856-1924), teve como autor o escritor e sócio correspondente Luiz Francisco da Veiga (1834-1899) ${ }^{4}$.

Algumas biografias eram extraídas de outros periódicos como O Panorama, o Ostensor Brasileiro, Jornal do Comércio e Minerva Brasiliense, ou mesmo de obras como a Biblioteca Lusitana do abade Diogo Barbosa Machado. Estes trabalhos estavam sujeitos às críticas e

\footnotetext{
${ }^{4}$ As quatro "ilustres brasileiras" biografadas por Joaquim Norberto distinguiram-se pelas armas. Rosa Maria Siqueira e Maria Ursula de Abreu Lencastre tiveram suas biografias publicadas em 1841. A biografia de Clara Fillipa Camarão surgiu no periódico em 1848 e a de Damiana da Cunha, em 1861. (R.IHGB, 1861, p. 530).
} 
pareceres antes de figurarem no periódico do IHGB e muitas vezes se publicavam aditamentos para corrigir erros que porventura passassem despercebidos na primeira publicação.

A seção destinada às biografias era vedada aos sócios, porém, isto não impediu que alguns deles figurassem seus nomes ao lado das ilustres personalidades, como foram os casos do visconde de São Leopoldo (1774-1847), do Marquês de Sapucaí (1795-1843), respectivamente os dois primeiros presidentes do IHGB. Na seção figuraram nomes como o do cônsul geral da Rússia Henrique Júlio de Wallestein (1790-1843) além de Balthazar da Silva Lisboa (1761-1840), Manoel Odorico Mendes (1799-1864), Gonçalves de Magalhães, Antônio Francisco Dutra e Mello (1823-1846), José Eloy Pessoa (1792-1841) e Joaquim Caetano da Silva (1810-1843).

Aos sócios falecidos era reservado outro espaço no periódico, localizado aos finais das sessões de aniversário, por meio dos discursos dos oradores oficiais do grêmio. Cabia também aos oradores o pronunciamento de um discurso fúnebre na cerimônia de sepultamento dos consócios. Esses rituais que se repetiam anualmente eram realizados publicamente e possuíam espaço garantido na Revista. Uma forma de promoção da instituição e de seus artífices, “o elogio dos mortos e a consagração dos vivos" (OLIVEIRA, 2007, p. 162).

\section{Os não-ditos da História do Brasil}

No primeiro meio século de publicação, houve uma nítida preferência por evidenciar as incursões ao interior do território brasileiro. Era imprescindível o conhecimento das províncias consideradas distantes, ainda mais se seus territórios servissem de fronteira nacional, que mediavam a linha de limites das terras pertencentes às ex-colônias espanholas. Essa temática de fronteira, quase sempre se entrecruzava com outros temas abordados, mais diretamente com questões relacionadas a indígenas. Era necessário se conhecer os usos, costumes e territórios habitados por essas sociedades a fim de integrá-las como mão de obra, utilizando-se do eufemismo "civilizá-las".

Essa busca pelo conhecimento do interior e pela legitimação dos territórios conquistados à Espanha se deu de forma mais contundente nos primeiros anos, durante a fase de afirmação da Monarquia. A partir da década de 1850, fase da consolidação do Império, esses números foram gradativamente diminuindo. 
Visivelmente um grupo não teria espaço na formação da nação, de acordo com as publicações: o negro. Dos cinco trabalhos que figuraram no periódico, no Segundo Império, dois deles referem-se à destruição do Quilombo dos Palmares, outros dois foram temas de Programas Históricos desenvolvidos por Cunha Barbosa e José Silvestre Rebello. Para o primeiro secretário, o negro estava "embaraçando a civilização do indio" e, para Rebello, a culpa não era apenas dos "semibrutos escravos", mas também, e, principalmente "á ignorancia dos feitores" (R.IHGB, 1839, p. 159-172).

Em 1888, ano da Lei Áurea e do jubileu do Instituto, saiu publicada a Extincção da escravidão no Brasil. Nesse texto, sem autoria declarada, aparece o decreto da princesa Izabel, libertando os cativos e a transcrição dos discursos de alguns dos membros do IHGB proferidos no Paço. Nestes, em tom de elogio à "iniciativa" da regente e aos feitos do Conde d'Eu (1842-1922) nos campos do Paraguai, durante a guerra, a comitiva tratou o fato como um desdobramento das ações de políticos, sócios do Instituto, como o visconde do Rio Branco (1819-1880), autor da lei de 1871, conhecida por "ventre livre", e do finado sócio Agostinho Marques Perdigão Malheiro (1824-1881), que pela sua obra A escravidão no Brazil, lida diversas vezes nas reuniões, mas não publicada, teria "lançado os fundamentos da extincção do captiveiro".

\section{Pareceres das obras e Programas históricos}

Os Programas históricos constituíam-se por temáticas consideradas como "duvidosas", que eram desenvolvidas pelos sócios nas sessões, sorteadas, ou então, indicadas pelo Imperador, a partir de sua participação nas reuniões. O interessante é que só uma pequena parcela dos assuntos discutidos foi publicada nas páginas do periódico do IHGB. Pelas Atas, percebe-se um total de 60 Programas desenvolvidos e discutidos nas Sessões Ordinárias. Desses, apenas 15 deles obtiveram publicidade durante o Segundo Reinado (Cf. DIAS, 2009).

Inicialmente os Programas eram sorteados e um dos sócios voluntariamente se encarregava de desenvolvê-lo nas reuniões subsequentes. $\mathrm{O}$ acúmulo de temas e a omissão dos associados fizeram com que eles passassem a ser designados pela mesa diretora, ou, a partir de 1849, pelo próprio Pedro II. Na sua primeira participação na Sessão Ordinária, o jovem imperador já ordenou que fossem desenvolvidos os Programas já aprovados e distribuiu mais quatro temas para os sócios desenvolverem o mais breve possível (R.IHGB, Ata da sessão de 15/12/1849). 
Entre os publicados, figuram temáticas como a periodização da história do Brasil, catequização indígena, modos de obtenção de documentos nas províncias, origem da cultura do anil, guerreiras Amazonas no Brasil, animais trazidos pelos conquistadores, plantas exóticas aclimatadas, e, até mesmo um estudo sobre a ocorrência de terremotos em solo nacional.

Porém, entre os que foram lidos nas sessões, mas não publicados, encontram-se Programas sobre: a forma de administrar os índios pelos jesuítas; se os poetas românticos impedem o desenvolvimento da poesia nacional; a origem da raça dos ciganos e sobre a introdução de estrangeiros para as minas de ouro.

Há também os que foram sorteados e/ou designados, mas não chegaram a ser lidos e muito menos publicados. Entre eles temas como: história dos indígenas; vestígios de civilização anterior a chegada dos portugueses; se os escravos são tratados com maior ou menor cuidado do que em outros países; efeitos imediatos da mudança da Corte; primeiros americanos a tentarem obter a independência; motivo do atraso da colonização no Rio de Janeiro; inexistência de tipografias no Brasil e a suspeita do não auxílio de Lisboa para com a guerra com os holandeses.

Os Juízos e Pareceres, uma preocupação do IHGB em avaliar a produção sobre o Brasil, contribuíram também para apontar caminhos que levassem à construção da narrativa histórica nacional, ainda por fazer.

Com relação aos pareceres, havia os que foram lidos e discutidos nas sessões e vieram à público, os que foram apenas lidos mas não publicados e os que foram ignorados, ou seja, nem lidos, muito menos saíram no periódico. Como exemplo do primeiro caso, tem-se um parecer sobre o trabalho de José Joaquim Machado de Oliveira (1790-1867) sobre os limites entre Brasil e Uruguai. Para o segundo caso, a análise de Manoel Ferreira Lagos sobre a viagem do conde de Castelnau e para o último caso, obras como Le Brésil, de Ferdinand Denis e a História Geral do Brasil, de Varnhagen simplesmente ficaram sem manifestações por parte do Instituto.

\section{Obras comentadas e publicadas}

Uma grande polêmica tomou conta da sala de reuniões do IHGB em torno da memória de Machado de Oliveira (R.IHGB, 1853, p. 393-432). Fazendo uma longa digressão sobre os Tratados de limites entre as Coroas ibéricas, e depois entre o Império brasileiro e o Uruguai, 
criticou a intervenção armada na Banda Oriental e enfatizou que o Brasil foi prejudicado pela perda de territórios devido ao estipulado no Tratado de limites de 12/10/1851.

O primeiro parecerista, o conselheiro Duarte da Ponte Ribeiro (1795-1878), declarou que a memória não era condizente com a atuação do Império no Prata e recomendou ao Instituto que não desse assentimento a essa reflexão, contrária à retidão que caracteriza a política brasileira (R.IHGB, 1853, p. 435-460). O segundo parecer, de autoria do também conselheiro Candido Baptista de Oliveira (1801-1865), em defesa do autor da memória, declarou ser o trabalho digno do apreço do Instituto e para o futuro historiador.

Gonçalves Dias (1823-1864) entrou no embate, analisando tanto a memória de Machado de Oliveira como o parecer de Ponte Ribeiro, porém posicionando-se em favor da memória: “conclúo que não se affastará o Instituto de nenhum principio de rectidão e justiça, mostrando-se indulgente para com a "memoria historica" do nosso digno collega o Sr. Machado de Oliveira” (R.IHGB, 1853, p. 478-514).

A atitude do autor dos Timbiras levou Duarte da Ponte Ribeiro a apresentar uma defesa do seu parecer, acompanhado por vários apensos que comprovavam sua argumentação (R.IHGB, 1853, p. 515-554). Pedro de Alcântara Bellegarde (1807-1864), com espírito conciliador, observou alguns pontos sobre os Tratados de limites, rogando ao Instituto que "aparte toda discussão que azede os espíritos e estabeleça desconfianças". Em seguida, sugere que se nomeie uma comissão a fim de elaborar uma coleção de todos os Tratados, convenções, notas, declarações ou quaisquer outros atos relativos aos limites (R.IHGB, 1853, p. 555-557).

Cerca de um mês depois da apresentação da defesa do parecer, Gonçalves Dias apresentou uma resposta, na qual concluiu que as reflexões de Baptista de Oliveira e as Notas de Bellegarde arrematavam em sentido quase idêntico à memória de Machado de Oliveira e sugeriu ao Instituto que ache a referida memória de utilidade, ainda que alguns fatos precisem ser retificados (R.IHGB, 1853, p. 558-572).

Diante de tantos impasses acerca dessa disputa de memória, a mesa diretora decidiu que todos os textos fossem impressos no mesmo número da Revista, sem interpor juízo algum sobre a matéria. Dessa forma, o Instituto ratificava a sua postura imparcial diante de assuntos polêmicos (Cf. SGRIGNERO, 2010). Na Sessão Aniversária, ao final desse ano, Joaquim Manuel de Macedo (1820-1882), primeiro secretário, assim se referiu às discussões ocasionadas pela memória de Machado de Oliveira: 
As nossas sessões ordinarias foram durante todo o anno social celebradas com perfeita regularidade, e se fizeram recommendaveis pela apresentação e leitura de excellentes trabalhos, e por discussões meditadas e profundas, que lançaram grande cópia de luz sobre alguns pontos da historia patria, e das nossas questões de limites (R.IHGB, 1853, p. 580).

\section{Obras discutidas e não publicadas}

Outro episódio interessante ilustra o interesse exacerbado sobre um determinado assunto somente nas reuniões ordinárias, mas sem nenhuma intenção de torná-lo público. Trata-se do alvoroço que se formou no IHGB acerca da expedição científica francesa, comandada por Francis Castelnau (1810-1880), pelo interior do Brasil, entre os anos de 1843 e 1845.

O conde de Catelnau mantinha o Instituto a par de sua exploração no interior do território brasileiro, por meio de cartas. A que chegou de Lima, escrita em 20/02/1846, foi transcrita na Ata da sessão de 09/07/1846. Na missiva, o viajante relatou a travessia do continente, descrevendo a exploração do território pelos rios Araguaia, Tocantins, Cuiabá, depois pelo São Lourenço e Paraguai, no qual entre os diversos canais, ilhas e baías desse labirinto aquático o explorador acreditou ter achado um rio ainda desconhecido dos geógrafos, o qual o batizou com o nome de rio Pedro II, em honra ao Imperador brasileiro (R.IHGB, Ata da sessão de 09/07/1846).

Em 1851 o primeiro secretário Manoel Ferreira Lagos comunicou a chegada do primeiro volume da obra de Castelnau, e, informava que, como continha muitas inexatidões, propôs que se formasse uma comissão para examiná-la. Aprovada a proposta, foi indicado para esse trabalho, Joaquim Manuel de Macedo (R.IHGB, Ata da sessão de 09/05/1851).

O próprio Macedo quando assumiu a secretaria observou em relatório apresentado na Sessão Aniversária de 1853, as imprecisões do viajante francês: "commetendo inexatidões históricas, e acabando finalmente por ufanar-se até de ter sido o primeiro a navegar em rios, que desde longa data haviam sido explorados" (R.IHGB, 1853, p. 600).

Manoel Ferreira Lagos começou a ler a análise da viagem do conde francês a partir de maio de 1855, leitura que se estendeu durante 11 sessões seguidas. Na sessão de final de ano, Macedo assim se referiu ao conde:

O Sr. Ferreira Lagos não se contentou em um simples e breve juízo, que poderia ser laudativo ou contrario ao merito da obra sujeita á sua fina e profunda critica; não: acompanha passo a passo o viajante francez atravez 
das nossas provincias por elle vizitadas: dá-lhe a mão sempre que o vê tropeçar, e isso acontece muitas vezes: aponta um a um os erros numerozos que comete, marca-lhe os fatos que inventa; prova-lhe o conhecimento antigo, que nós temos de algumas das suas pretendidas descobertas; vinganos da maledicencia, e com um sopro vigorozo de potente lógica desfaz as creações imaginarias, que o conde de Castelnau quer fazer correr mundo com fóros de realidades. (...) mostra desfilando em estravagante revista a multidão de absurdos, de incongruências e contradições, e não poucas vezes de immerecidas injurias, com que desfiguram e calumniam o Brazil, homens que escondem o que vêem, que improvizam o que não existe, e que para escrever invocam a muza da mentira (R.IHGB, 1855, p. 506-507).

Até o presidente do Instituto, um cargo mais figurativo, e que dificilmente emitia críticas, não se conteve:

Em breve Srs., a Revista oferecerá á vossa estudioza curiosidade erudita e engenhoza analize da viagem do conde de Castelnau, d'essa viagem inçada de inexactidões, crespa de erros e frequentemente adversária da verdade nas couzas de nossa terra (R.IHGB, 1855, p. 480).

No ano de 1856, Lagos continuou a analisar a obra de Castelnau e na Sessão Magna, novamente o presidente da casa ratificou que em breve a engenhosa crítica da viagem do conde será franqueada ao público da Revista. O secretário Macedo informou que somente nesse ano a análise de Lagos chegou ao seu termo. O primeiro secretário, ao dar a notícia do término da leitura e análise dessa obra, repleta de imprecisões, demonstrou, perante o Imperador, que havia chegado a hora de se planejar uma viagem científica ao interior do país, executada por seus filhos.

Tal procedimento sugere a hipótese de que a utilização negativa da viagem do conde francês e pelas constantes críticas, durante praticamente dois anos, foi uma forma de se conseguir patrocínio para uma expedição nacional a fim de explorar as províncias do norte do país. A proposta de se criar uma comissão de brasileiros partiu do próprio Ferreira Lagos em 1856. Em janeiro de 1859 a expedição partiu do Rio de Janeiro em direção ao Ceará (Cf. LOPES, 1996, p. 50-64).

\section{Publicar ou arquivar? Algumas considerações}

Após a análise das temáticas selecionadas para compor as edições do periódico do IHGB, durante os primeiros cinquenta anos de atividade, pode-se inferir que apesar da ênfase 
na história do passado colonial e da busca de se constituir um acervo documental, o Instituto procurou, em seus diversos momentos, deixar claro o tipo de história que deveria ser escrita, a partir da seleção cuidadosa dos fatos para serem lembrados e das personagens dignas de entrar para a galeria das biografias dos brasileiros ou indivíduos ilustres. Os pontos ainda obscuros da história eram discutidos e elucidados nas reuniões, em forma de Programas históricos, os Elogios aos sócios falecidos eram realizados como forma de se perpetuar a própria memória do Instituto, através das realizações de seus componentes. Uma lógica de publicação acerca das províncias obedecia a articulação entre o conteúdo do texto selecionado e o contexto político vivido pelo Império. O passado deveria fornecer respostas para as demandas do tempo presente.

O fato, por exemplo, de as regiões envolvidas em conflitos de contestação da ordem imperial serem vetadas pelas comissões de História ou de Redação nas duas primeiras décadas do Segundo Reinado, ou serem estimuladas à publicação com certa regularidade nas duas décadas finais, ilustra bem essa lógica: a publicação ou o arquivamento de temas regionais, cujas províncias foram palco de movimentos separatistas, ia de encontro ao projeto de unidade nacional que a Revista devia estimular, assim como divulgá-las num determinado momento, após o término da guerra no Prata e à época do lançamento do Manifesto Republicano podia servir de alerta para uma possível realidade trazida pelos ideais republicanos, agora muito mais fortes do que no período regencial.

$\mathrm{Na}$ Revista está visível (e disponível para novos estudos) o ambicioso projeto do IHGB, constituindo-se em um lócus privilegiado para a pesquisa, nos termos de Manoel Salgado Guimarães, pois, além de registrar as atividades do Instituto, por meio de seus Relatórios e das Atas das sessões e divulgar cerimônias e atos comemorativos diversos, suas páginas se abriram à publicação de documentos como forma de preservar a informação neles contidos. Por meio das produções dos sócios, como as biografias, os necrológios, os pareceres de obras ofertadas ao grêmio e nos desenvolvimentos dos programas históricos, aparecem os indicativos de uma história para o Brasil. Um certo tipo de história, "submetida à memória" (GUIMARÃES, 2003, p. 23), mas ainda assim, uma história. Restringir a Revista a apenas um depositário de memória é descartar todos os mecanismos inerentes à Operação historiográfica empreendida pela agremiação.

\section{Fontes}


Revista do Instituto Histórico e Geográfico Brasileiro (R.IHGB). Tomos I, a LII (1839-1889). Disponível em: http://www.ihgb.org.br/rihgb.php. Acesso em 30/06/2015.

\section{Referências}

ARAUJO, Valdei Lopes de. A experiência do tempo: conceitos e narrativas na formação nacional brasileira (1813-1845). São Paulo: Hucitec, 2008.

CERTEAU, Michel de. Operação Historiográfica. In: A Escrita da História. Rio de Janeiro: Forense Universitária, 2002, p. 65-106.

CEZAR, Temístocles. Presentismo, memória e poesia. Noções da escrita da História no Brasil oitocentista. In: PESAVENTO, Sandra Jatahy. (org.). Escrita, linguagem, objetos: leituras de história cultural. Bauru - SP: EDUSC, 2004, p. 55.

DIAS, Fabiana Rodrigues. Por entre legados e demandas: um estudo sobre os programas históricos apresentados no Instituto Histórico e Geográfico Brasileiro (1838-1856). Dissertação de Mestrado em História. UERJ, Rio de Janeiro, 2009.

GUIMARÃES, Lúcia Maria Paschoal. Debaixo da imediata proteção de Sua Majestade Imperial: o Instituto Histórico e Geográfico Brasileiro (1838-1889). R.IHGB. Rio de Janeiro, ano 156, n. 388 , jul./set. 1995 , p. 513.

GUIMARÃES, Manoel Luiz Salgado. Nação e civilização nos trópicos: o Instituto Histórico e Geográfico Brasileiro e o projeto de uma história nacional. Estudos Históricos. Rio de Janeiro, n. 01, 1988, p. 20.

A Revista do IHGB e os temas de sua historiografia (1839-1857). Fazendo a história nacional. In: WEHLING, Arno. (Coord.). Origens do IHGB: ideias filosóficas e sociais e estrutura de poder no Segundo Reinado. Rio de Janeiro: IHGB, 1989.

A cultura histórica oitocentista: a constituição de uma memória disciplinar. In: PESAVENTO, Sandra Jatahy (org.) História cultural: experiências de pesquisa. Porto Alegre: Ed. Da UFRGS, 2003, p. 9-24.

KOSELLECK, Reinhart. História, histórias e estruturas temporais formais. In:

Futuro Passado: contribuição à semântica dos tempos históricos. Rio de Janeiro: Contraponto: Ed. PUC - Rio, 2006, p. 119.

LEOTTI, Odemar. Instituto Histórico e Geográfico de Mato Grosso - IHGMT: relações de poder, escrita, política, cientificidade e a invenção do mato-grossense moderno (1895 a 1934). Tese (Doutorado em História) - Universidade Estadual Paulista, Assis, 2013.

LUCA, Tânia Regina de. História dos, nos e por meio dos periódicos. In: PINSKY, Carla Bassanezi (org.) Fontes históricas. 2a ed. São Paulo: Contexto, 2008, p.140.

LOPES, Maria Margaret. "Mais vale um jegue me carregue, do que um camelo que me derrube”...lá no Ceará. Manguinhos, vol. 3, 1996, p. 50-64. 
MAHL, Marcelo Lapuente. O paulista e o outro: a constituição de uma identidade racial no Instituto Histórico e Geográfico de São Paulo (1894-1940). In: FERREIRA, Antonio Celso; MAHL, Marcelo Lapuente (Org.). Letras e identidades: São Paulo no século XX, capital e interior. São Paulo: Annablume, 2008.

Teorias raciais e interpretação histórica: O Instituto Histórico e Geográfico de São Paulo (1894-1940). Dissertação (Mestrado em História) - Universidade Estadual Paulista. Assis, 2001.

OLIVEIRA, Maria da Glória. Traçando vidas de brasileiros distintos com escrupulosa exatidão: biografia, erudição e escrita da história na RIHGB (1839-1850). História, São Paulo, v. 26, n. 1, 2007, p. 154-178.

RIBEIRO, Mariana dos Santos. Construindo histórias e memórias: O IHGB e o IAGP em meio às celebrações do centenário do movimento pernambucano de 1817. Tese (Doutorado em História Social da cultura) - Pontifícia Universidade Católica, Rio de Janeiro, 2011.

RODRIGUES, Neuma Brilhante. $O$ amor da pátria, o amor das letras: as origens da nação na Revista do Instituto Histórico e Geográfico Brasileiro (1839-1889). Dissertação (Mestrado em História) -UNB, Brasília, 2001, p. 55-56.

SGRIGNERO, Adriano Augusto. Em busca da originalidade e unidade da nação: razões e critérios para uma História Geral do Brasil segundo os Pareceres e Juízos publicados pela RIHGB (1838-1860). Dissertação (Mestrado em História) -UNICAMP, Campinas, SP, 2010.

SIRINELLI, Jean-François. Os intelectuais. In: RÉMOND, René. Por uma história política. Rio de Janeiro, Ed. da UFRJ, 1996.

WEHLING, Arno. De formigas, aranhas e abelhas: reflexões sobre o IHGB. Rio de Janeiro: Instituto Histórico e Geográfico Brasileiro, 2010. 